\title{
Erratum: Total elbow arthroplasty: history, current concepts, and future
}

\section{Saccomanni Bernardino}

Published online: 27 November 2010

(C) Clinical Rheumatology 2010

\section{Erratum to: Clin Rheumatol}

DOI 10.1007/s10067-010-1539-7

This article has been retracted due to plagiarism.

The online version of the original article can be found at http://dx.doi. org/10.1007/s10067-010-1539-7.

S. Bernardino $(\bowtie)$

Orthopaedic and trauma Surgery, University of Chieti (Italy),

via dei Vestini,

66013, Chieti Scalo, Italy

e-mail: bernasacco@yahoo.it 